\title{
Reciprocity and Social Exchange in the Sharing Economy
}

\author{
Dinara Davlembayeva ${ }^{1}$, Savvas Papagiannidis ${ }^{2}$ and Eleftherios Alamanos ${ }^{3}$ \\ ${ }^{123}$ Newcastle University Business School, Newcastle upon Tyne, NE1 4SE, United King- \\ dom \\ d.davlembayeva2@newcastle.ac.uk \\ savvas.papagiannidis@ncl.ac.uk \\ eleftherios.alamanos@ncl.ac.uk
}

\begin{abstract}
This study pursued two objectives: 1) it comprehensively investigated the role of the factors facilitating social exchange, reciprocity expectation and social value in use behaviour, and 2) it examined the effect of the sharing economy on social inclusion and subjective well-being. The data were collected from 487 users of different sharing economy platforms in the United States. Structural equation modelling was employed to analyse the correlation of the examined variables. The results demonstrated the positive effect of egoistic belief, reciprocity norm, social value, and the negative effect of identification on the use of the sharing economy. In addition, strong relationships between use behaviour and outcomes were identified. Future research suggestions are provided.
\end{abstract}

Keywords: sharing economy, social exchange, social capital, factors of use behaviour, subjective well-being, social inclusion.

\section{Introduction}

The sharing economy is an emergent socio-economic system that has been growing fast, affecting the values and purchasing behaviour of consumers [1]. However, the academic literature exploring the driving forces of collaborative consumption is still scarce, providing little empirical evidence of the consumers' perspective on the phenomenon $[2,3]$. The observed effect of the sharing economy on individuals' preferences signals the need for further empirical investigation of consumer behaviour in the context of the new socio-economic system.

Given the above, this study aims to address three main gaps in the literature. First, due to the socio-economic nature of the sharing economy, the literature has been split into two streams - the economic and the social one -each of which focuses on different drivers of the system development and the users' motives for participation [4]. Due to the divergent focuses of the two streams of the literature, the role of the key drivers of collaborations, such as psychological (e.g. expected reciprocity) and social factors, has not been explored. The second gap refers to the tendency of the previous research to collect data from consumers of particular platforms, such as the Airbnb accommodation sharing system and the Uber ridesharing service [5, 6]. In addition, the 
comprehensiveness of the current research is limited by the focus on single factors, such as trust, price and cultural values $[7,8]$. Thirdly, due to the focus on the wider scale of the sharing economy impact (i.e. institutional change and environmental sustainability) $[9,10]$, the users' perceived benefits of collaborative consumption in terms of access to society, resources and well-being have not been explored. To address the above gaps, there are three main objectives of the paper: 1) to examine psychological factors of collaborations, 2) to employ an overarching approach to examine key social factors driving collaborations in different sharing economy segments, and 3) to provide empirical evidence of the effect of the sharing economy on perceived social inclusion and well-being.

\section{Literature Review and Hypotheses}

\subsection{Sharing Economy: Definition and Theoretical Foundation}

The literature revolves around two main approaches of conceptualising practices carried out in the sharing economy. Botsman and Rogers [11] define collaborative consumption as an act of "swapping, sharing, bartering, trading and renting being reinvented through the latest technologies and peer-to-peer marketplaces". This definition places purely commercial (e.g. renting and trading) and non-compensated practices (e.g. sharing, swapping) of resources redistribution under one umbrella. In contrast, Belk [12] postulates that collaborative consumption is different from sharing, gift-giving and commodity exchange. The latter three concepts are differentiated by the type of reciprocity and ownership control over sharable objects. Sharing and gift-giving are socially bonding practices. They are carried out without the obligation or expectation of immediate return $[13,14]$, whereas commodity exchange denotes mutual and immediate reciprocity. In addition, sharing enables temporary access to a resource for use, such as Couchsurfing communities that offer free accommodation for travellers. Giftgiving and commodity exchange provide a complete transfer of resources ownership from one person to another [14]. For example, the Freecycle community makes it possible to prolong the lifecycle of used items by gifting them to other members of the platform. However, commodity exchange resembles a marketplace transaction, excluding social relations between parties. The exchange is immediate and negotiated, without lingering returns. Finally, collaborative consumption denotes compensated practices, which embrace different types of ownership control. It is defined as an act of "people coordinating the acquisition and distribution of a resource for a fee or other compensation" [12]. Despite the economic outcomes of relations, it is people, rather than the market, that regulate transactions.

From the theoretical perspective, collaborative consumption can be explained by the social exchange framework. Social exchange is defined as "the exchange of activity, tangible or intangible, and more or less rewarding or costly, between at least two persons or more" [15]. There are three main premises of social exchange. First, social exchange is contingent on social capital, which refers to social entities, such as norms, 
values, rules, trust, expectations, obligations and information channels, to name a few. These social entities enable the functioning of social groups by both facilitating and inhibiting social relations and their consequences [16-19]. Second, social exchange results from the subjective evaluation of the costs and rewards of exchange with the purpose of ensuring reciprocal relations. The third premise of social exchange is that the value of rewards and the fairness of costs incurred by transactions is dependent on individuals' perception, thus it is a subjective process $[15,20]$. In line with the above, collaborative relations in the sharing economy represent the effect of factors facilitating or hindering social exchange, the outcome of the evaluation of expected benefits and costs resulting from the lack of reciprocity.

\subsection{Hypothesis Development}

\section{Social Capital Factors}

To examine the facilitating role of social capital factors in collaborative relations, we used the framework developed by Nahapiet and Ghoshal [16]. The framework by Nahapiet and Ghoshal [16] was developed for organisational settings, which was later adapted to a private context $[17,21]$. Given the context of the study, we adopted the later version of the framework for the hypothesis development.

Structural Social Capital Factor: Structural social capital represents properties of social systems, facilitating social interaction and helping develop social networks [19]. Structural social capital enables the development of bonding ties within communities representing direct relationships between community members. Bonding ties are characterised by strong connections resulting from the repeated interactions of parties [18]. There is evidence that social ties have both direct and mediated effects on collaborative practices $[17,21,22]$. Bonding ties have an indirect effect on behaviour through interpersonal trust [21]. Several studies tested the direct influence of connections on the use of online communities $[17,22]$. However, the significance of the factors was not confirmed in the context of accommodation sharing [2]. The inconsistency of findings in the previous literature could be due to the difference in the strength of ties, rather than the frequency. Hence, the first hypothesis states that: H1: Bonding social ties have a positive effect on the use of sharing economy
platforms.

Cognitive Social Capital Factor: Cognitive social capital represents resources enabling shared cognition, representation and interpretation of things and events [16, 17]. Shared vision underpins the work of communities by uniting their members through common goals, ideas and rules of conduct. Shared vision enables effective interpersonal communication, facilitates understanding and stimulates individuals' contribution to communities [21]. This social capital factor was studied in the context of collective practices $[2,17,21]$. It was found that the factor had an indirect relationship with use behaviour through interpersonal trust [21]. However, another study provides opposite results suggesting that shared vision negatively affects behaviour. Conflicting results require a further examination of the effect of shared vision on use behaviour: 
H2: Shared vision has a positive effect on the use of sharing economy platforms

Relational Social Capital Factors: Relational social capital represents relationship characteristics facilitating the development of relations, such as cooperative norms, interpersonal trust, obligations/expectations to cooperate and social identification with other group members $[16,18,19]$. Identification is defined as "one's conception of self in terms of the defining features of self-inclusive social category" [23]. Identification reflects the sense of belonging, loyalty and commitment to communities [16]. Previous literature gives an account of the indirect effect of identification on individuals' behaviour [3, 24]. Particularly, identification with social groups had a positive effect on the perception of encouragement and usefulness of social networking websites, which further lead to actual use [24]. Given the above, we hypothesise that:

H3: Identification has a positive effect on the use of sharing economy platforms

The literature on the sharing economy has strongly discussed the association between pro-environmental beliefs and norms and collaborative consumption [25, 26]. Sustainability was found to be the key factor driving the intention to share accommodation and use online marketplace platforms [27]. Theoretically, the above findings are supported by the value-belief-norm theory by Stern [28]. This theory argues that biospheric, altruistic and egoistic values activate the beliefs in adverse consequences, which affect the formation of personal norms underpinning pro-environmental behaviour. Biospheric belief refers to the belief that the environment is under threat and requires urgent actions to be protected. Altruistic belief is associated with pro-social values, while egoistic belief causes the resistance to protecting the environment due to the belief that proenvironmental behaviour can harm oneself [28]. Drawing on the above, this study hypothesises that:

H4: a) altruistic and b) biospheric beliefs have positive effects on the use of sharing economy platforms; c) egoistic beliefs have a negative effect on the use of sharing economy platforms.

The reciprocity norm represents the two factors of social capital (i.e. obligations and norms), which refers to the obligations to reciprocate and the belief that the act of exchange should always be reciprocated [20]. Relationships in the sharing economy are built upon two forms of reciprocity, which are negotiated and generalised ones. It was found that knowledge sharing in virtual communities was motivated by expected reciprocity [29]. Similarly, in market-based transactions, individuals' engagement in collaborations is contingent on the perception of reciprocal rewards [30]. Based on the above-mentioned discussion, the fifth hypothesis states that:

H5: Reciprocity norm has a positive effect on the use of sharing economy platforms 


\section{Perceived Social Values}

According to Holbrook and Corfman [31], perceived social value refers to the belief that certain events or the attainment of objects represent symbolic meaning and help achieve a certain status/role in the society. Individuals may be driven by personal needs to establish social relationships and engage in exchange $[32,33]$. For example, one of the drivers of participation in the sharing economy is the development of social networks through repeated interactions with other peers [27,34]. Also, the engagement in collaborative practices may help individuals to establish identity with the group [32, $33,35,36]$. The development of social identity may help members receive the benefits of their group and establish the image that is favourable by the society. Based on the above:

H6: Perceived social values have a positive effect on the use of sharing economy platforms.

\section{The Outcomes of Using Sharing Platforms}

In the context of this study, the outcomes of the use of sharing platforms reflect the degree to which people satisfy their goals $[10,27,37]$. There are two forms of potential sustained benefits of collaborations in the sharing economy, which refer to social inclusion and subjective well-being. Social inclusion happens when people get access to economic benefits and resources, access to social services, feel integrated with the society at the interpersonal (i.e. family, social network) and legal levels (i.e. equal citizens in society) [38]. Subjective well-being results from the subjective evaluation of one's own standard of living and perceived level of happiness [39]. Both subjective wellbeing and social inclusion may result from social network development, identification with a community, the access to goods and services which otherwise would not be available, the development of self-confidence, and the engagement in meaningful activity for the society and the environment $[25,40]$. Hence this study posits that:

H7: The use of sharing economy platforms has a positive effect on a) social inclusion and b) subjective wellbeing.

\section{$3 \quad$ Methodology}

Considering the focus of the study, the utilisation of online questionnaires as a data collection tool was deemed appropriate. An independent company was involved in the distribution of questionnaires to respondents in the United States. Former and current users of platforms were eligible to participate. The questionnaire was designed in a way to ensure confidentiality and gather respondents' profiles, such as social and demographic data. The final sample of respondents comprised 487 people, which made it possible to run a statistical analysis of the correlation of the proposed variables [41]. The sample consisted of $48.7 \%$ male and $51.3 \%$ female respondents with almost half of them being over 50 years old $(49.3 \%)$. The majority of the respondents were either full-time $(57.5 \%)$ or part-time $(12.1 \%)$ employed, had a college graduate degree 
(34.3\%), received an annual income between 50,000 and 74,999 US dollars (26.1\%) or over 100,000 US dollars (25.1\%).

The questionnaire included 57 items related to eleven main constructs. The items for social capital derived from adapted scales measuring bonding social ties [29], shared vision, [21, 42], identification [29], the reciprocity norm [17, 43, 44] and three types of pro-environmental beliefs [45]. Social value scale originated from the study by Rintamäki, Kanto [46], while use behaviour derived from the IS literature [47-50]. The items for social inclusion were adopted from Richardson and Le Grand [51], and subjective well-being was measured by the scale developed by Diener et al. [52]. The responses were measured by a 7-point Likert scale with anchors between "1 - strongly disagree" to "7 - strongly agree".

SPSS v.24 and SPSS Amos v.24 were employed to analyse the collected data. To test the validity and reliability of the constructs, we ran the confirmatory factor analysis by following the guidelines suggested by Hair [41]. The results of the CFA analysis were satisfactory $(\chi 2(1484)=3748.23, \mathrm{CMIN} / \mathrm{DF}=2.526, \mathrm{CFI}=0.926, \mathrm{RMSEA}=0.056)$. Factor loading $(>0.7)$, average variance extracted (AVE $>0.5)$, construct reliability (C.R. $>0.7)$ and Cronbach's $\alpha(>0.7)$ confirmed the reliability of the measurements [41]. The result of the convergent validity test showed no validity issues (Table 2). To test the relationship between constructs, the structural equation modelling was conducted using Amos v.24.

Table 2. Convergent validity test

\begin{tabular}{lccccccccccc}
\hline & $\mathbf{1}$ & $\mathbf{2}$ & $\mathbf{3}$ & $\mathbf{4}$ & $\mathbf{5}$ & $\mathbf{6}$ & $\mathbf{7}$ & $\mathbf{8}$ & $\mathbf{9}$ & $\mathbf{1 0}$ & $\mathbf{1 1}$ \\
SI & .77 & & & & & & & & & & \\
ST & .04 & .94 & & & & & & & & & \\
Rec & .29 & .67 & .90 & & & & & & & & \\
ID & .16 & .79 & .85 & .91 & & & & & & & \\
SV & .12 & .80 & .80 & .87 & .90 & & & & & & \\
AB & .32 & .34 & .49 & .43 & .40 & .84 & & & & & \\
BB & .28 & .27 & .43 & .34 & .34 & .81 & .85 & & & & \\
SV & .28 & .66 & .75 & .83 & .77 & .46 & .43 & .86 & & & \\
EB & .16 & -.43 & -.30 & -.40 & -.43 & .06 & .01 & -.35 & .88 & & \\
US & .54 & .40 & .61 & .54 & .53 & .41 & .38 & .66 & -.02 & .82 & \\
WB & .37 & .57 & .67 & .70 & .63 & .48 & .47 & .79 & -.24 & .71 & .88 \\
\hline
\end{tabular}

Notes: Diagonal figures represent the square root of the average variance extracted (AVE) and the figures below represent the between-constructs correlations 


\section{$4 \quad$ Results and Findings}

Considering The model fit indices were satisfactory, confirming the consistency of the proposed model with the collected data and the ability to examine paths' significance (Table 3). The model explained $57.6 \%$ of the variance for the behaviour of sharing economy users, $28.3 \%$ of the variance for the feeling of being socially included and $54.8 \%$ for the perception of their subjective well-being. The coefficients of path analysis are provided in table 3 .

Table 3. The results of the test of hypotheses

\begin{tabular}{|c|c|c|c|c|c|}
\hline $\boldsymbol{H}$ & Path & & & Coef. & $(t$-test $)$ \\
\hline H1 & Social Ties & $--->$ & Use Behaviour & -0.031 & $(-0.478 \mathrm{~ns})$ \\
\hline $\mathrm{H} 2$ & Shared Vision & $--->$ & Use Behaviour & 0.087 & $(1.019 \mathrm{~ns})$ \\
\hline H3 & Identification & $--->$ & Use Behaviour & -0.23 & $\left(-2.024^{*}\right)$ \\
\hline $\mathrm{H} 4 \mathrm{a}$ & $\begin{array}{l}\text { Altruistic } \\
\text { Belief }\end{array}$ & $--->$ & Use Behaviour & 0.009 & $(0.118 \mathrm{~ns})$ \\
\hline $\mathrm{H} 4 \mathrm{~b}$ & $\begin{array}{l}\text { Biospheric } \\
\text { Belief }\end{array}$ & $--->$ & Use Behaviour & 0.029 & (0.373ns) \\
\hline $\mathrm{H} 4 \mathrm{c}$ & $\begin{array}{l}\text { Egoistic } \\
\text { Belief }\end{array}$ & $--->$ & Use Behaviour & 0.219 & $(4.907 * * *)$ \\
\hline H5 & Reciprocity & $--->$ & Use Behaviour & 0.357 & $(4.399 * * *)$ \\
\hline H6 & Social Value & $--->$ & Use Behaviour & 0.631 & $\left(8.041^{* * *}\right)$ \\
\hline $\mathrm{H} 7 \mathrm{a}$ & $\begin{array}{l}\text { Use } \\
\text { Behaviour }\end{array}$ & $--->$ & $\begin{array}{l}\text { Social } \\
\text { Inclusion }\end{array}$ & 0.532 & $\left(10.186^{* * *}\right)$ \\
\hline $\mathrm{H} 7 \mathrm{~b}$ & $\begin{array}{l}\text { Use } \\
\text { Behaviour }\end{array}$ & $--->$ & $\begin{array}{l}\text { Subjective } \\
\text { Well-Being }\end{array}$ & 0.74 & $(13.985 * * *)$ \\
\hline
\end{tabular}

Method: $M L ;$ SEM Model fit: $\chi 2(1501)=4011.336, C M I N / D F=2.672, C F I=0.918$, RMSEA $=0.059$

The paper examined the influence of eight antecedents on use behaviour: social ties, shared vision, identification, reciprocity, biospheric, egoistic and altruistic beliefs and social value $(\mathrm{H} 1-\mathrm{H} 6)$. Hypotheses 1, 2, 4a-b were not supported, suggesting that social ties, shared vision, biospheric and altruistic beliefs do not underpin the behaviour of sharing economy users. The paper gives insight into the relationship between use behaviour and social ties, which have been studied in the prior literature providing controversial findings (e.g. [2, 17, 22]). The finding of this paper demonstrates that the strength of social ties does not condition the use of sharing economy platforms. Similarly, users' participation in the sharing economy is not dependent on the views that they share with other members of sharing platforms. Previous research providing contradictory results partially explains this finding [29]. Shared vision had a different effect on the behaviour of different platform users. Therefore, future research should test the effect of the construct by controlling for the type of activity and platform. When it 
comes to the effect of biospheric and altruistic beliefs, the insignificant effect on use behaviour is consistent with the study by Möhlmann [53]. The author concluded that pro-environmental beliefs are not significant for monetary-based practices, such as accommodation and car sharing. A possible explanation could be that values driving behaviour are dependent on the type of sharing economy practice.

As a result of the study, hypotheses $3,5,4 \mathrm{c}, 6$ and $7 \mathrm{a}-\mathrm{b}$ were supported, confirming a positive relationship between identification, egoistic belief, reciprocity norm and social value. The effect of reciprocity norm was moderate and significant, supporting the findings of the prior literature on the domain of collaborative consumption and online exchange practices $[2,30]$. This finding supports the assumption that individuals' participation in collaborative practices is triggered by the expectation of either immediate or delayed reciprocation in the exchange of resources. A significant path between egoistic belief and use behaviour is inconsistent with the majority of the prior literature [24, 28]. However, it is logical considering that the insignificant effect of biospheric and altruistic beliefs was established. The plausible interpretation is that individuals are driven by personal needs that can go against social values, such as the contribution to the societal well-being and environment. When it comes to the relationship between identification and use behaviour, the results are negative, which contradicts evidence in the research on the social exchange domain $[3,24]$. This means that transactions in the sharing economy are not conditioned by a strong feeling of belonging to the sharing economy community, pride and collective self-esteem. Of all paths examining the antecedents of use behaviour, social value was found to be the strongest predictor of participation in the sharing economy. This finding suggests that the belief in fair allocation of resources among members of the community, the development of social relationships, the consistency of practices with individuals' lifestyle and image motivate collaborative consumption $[3,34,36]$.

Significant relationships between use behaviour, social inclusion and subjective wellbeing confirm that the participation in the sharing economy enables them to feel integrated with the society in terms of access to economic, social and legal resources, as well as achieving higher standards of living. The findings are consistent with the prior literature postulating a positive correlation between subjective well-being and collective-oriented practices [54].

\section{Conclusion}

The paper makes three contributions to the literature on the sharing economy domain. First, following the social exchange framework, the paper has investigated the role of social capital factors, the norm of reciprocity and values that shed light on the collective orientation of individuals engaging in collaborative relations. The study provides a comprehensive analysis of the effect of three types of factors facilitating social exchange that represent structural social capital, relational social capital and cognitive social capital $[16,17]$. The second contribution is that the study provides an insight into 
the drivers of the participation in the sharing economy by exploring the effect of social capital factors that have been controversial in the prior literature. The third contribution is that the paper empirically investigates the outcomes of the participation in the sharing economy, such as subjective well-being and perceived social-inclusion that have been a debatable topic in the previous research.

The paper has some limitations deriving from the adopted research design. Firstly, future research may adopt a longitudinal approach, that would make it possible to observe the dynamics in the perception of social inclusion and well-being over a certain timespan. Secondly, given the insignificance of some social factors and a positive relationship between egoistic belief and use behaviour, future research could examine the effect of utilitarian and monetary factors, such as price value, price sensitivity and price perception. Thirdly, to test the application of the model in other contexts, future studies could collect data in countries with different cultural values, beliefs and norms underpinning behaviour.

\section{References}

1. Wallenstein, J. and U. Shelat, What's Next for the Sharing Economy? Boston Consulting Group, 2017.

2. Kim, S., et al., Examining the influencing factors of intention to share accommodations in online hospitality exchange networks. Journal of Travel \& Tourism Marketing, 2017: p. 1-16.

3. Barnes, S.J. and J. Mattsson, Understanding collaborative consumption: Test of a theoretical model. Technological Forecasting and Social Change, 2017. 118: p. 281-292.

4. Davlembayeva, D., S. Papagiannidis, and E. Alamanos, 'Mapping the economics, social and technological attributes of the sharing economy. Information Technology \& People, 2019.

5. So, K.K.F., H. Oh, and S. Min, Motivations and constraints of Airbnb consumers: Findings from a mixed-methods approach. Tourism Management, 2018. 67: p. 224-236.

6. Boateng, H., J.P.B. Kosiba, and A.F. Okoe, Determinants of consumers' participation in the sharing economy: A social exchange perspective within an emerging economy context. International Journal of Contemporary Hospitality Management, 2019.

7. $\mathrm{Wu}, \mathrm{X}$. and J. Shen, A study on airbnb's trust mechanism and the effects of cultural values-Based on a survey of Chinese consumers. Sustainability, 2018. 10(9): p. 3041.

8. Lindblom, A., T. Lindblom, and H. Wechtler, Collaborative consumption as C2C trading: Analyzing the effects of materialism and price consciousness. Journal of Retailing and Consumer Services, 2018. 44: p. 244-252. 
9. Retamal, M., Product-service systems in Southeast Asia: Business practices and factors influencing environmental sustainability. Journal of Cleaner Production, 2017. 143: p. 894-903.

10. Fremstad, A., Does Craigslist Reduce Waste? Evidence from California and Florida. Ecological Economics, 2017. 132: p. 135-143.

11. Botsman, R. and R. Rogers, What's mine is yours: how collaborative consumption is changing the way we live. 2011: Collins London.

12. Belk, R., You are what you can access: Sharing and collaborative consumption online. Journal of Business Research, 2014. 67(8): p. 1595-1600.

13. Sahlins, M.D., Stone age economics. Vol. 130. 1974: Transaction Publishers.

14. Belk, R., Sharing. Journal of consumer research, 2010. 36(5): p. 715-734.

15. Homans, G.C., Human behavior: Its elementary forms. 1961, New York: Harcourt, Brace.

16. Nahapiet, J. and S. Ghoshal, Social capital, intellectual capital, and the organizational advantage. Academy of management review, 1998. 23(2): p. 242-266.

17. Wasko, M.M. and S. Faraj, Why should I share? Examining social capital and knowledge contribution in electronic networks of practice. MIS quarterly, 2005: p. 35-57.

18. Coleman, J.S. and J.S. Coleman, Foundations of social theory. 1994: Harvard university press.

19. Putnam, R.D., Tuning in, tuning out: The strange disappearance of social capital in America. PS: Political science \& politics, 1995. 28(4): p. 664-684.

20. Blau, P.M., Exchange and Power in Social Life. 1964, New York: Wiley. 352.

21. Tsai, W. and S. Ghoshal, SOCIAL CAPITAL AND VALUE CREATION: THE ROLE OF INTRAFIRM NETWORKS. Academy of Management Journal, 1998. 41(4): p. 464-476.

22. Ellison, N.B., C. Steinfield, and C. Lampe, The benefits of Facebook "friends:" Social capital and college students' use of online social network sites. Journal of computer-mediated communication, 2007. 12(4): p. 11431168.

23. Bagozzi, R.P. and U.M. Dholakia, Intentional social action in virtual communities. Journal of interactive marketing, 2002. 16(2): p. 2-21.

24. Kwon, O. and Y. Wen, An empirical study of the factors affecting social network service use. Computers in human behavior, 2010. 26(2): p. 254-263.

25. Hong, S. and H. Vicdan, Re-imagining the utopian: Transformation of a sustainable lifestyle in ecovillages. Journal of Business Research, 2016. 69(1): p. 120-136.

26. Aptekar, S., Gifts Among Strangers: The Social Organization of Freecycle Giving. Social Problems, 2016. 63(2): p. 266-283.

27. Tussyadiah, I.P., Factors of satisfaction and intention to use peer-to-peer accommodation. International Journal of Hospitality Management, 2016. 55: p. $70-80$. 
28. Stern, P.C., New environmental theories: toward a coherent theory of environmentally significant behavior. Journal of social issues, 2000. 56(3): p. 407-424.

29. Chiu, C.-M., M.-H. Hsu, and E.T. Wang, Understanding knowledge sharing in virtual communities: An integration of social capital and social cognitive theories. Decision support systems, 2006. 42(3): p. 1872-1888.

30. Shiau, W.-L. and M.M. Luo, Factors affecting online group buying intention and satisfaction: A social exchange theory perspective. Computers in Human Behavior, 2012. 28(6): p. 2431-2444.

31. Holbrook, M.B. and K.P. Corfman, Quality and value in the consumption experience: Phaedrus rides again. Perceived quality, 1985. 31(2): p. 31-57.

32. Belk, R.W., Possessions and the extended self. Journal of consumer research, 1988. 15(2): p. 139-168.

33. Solomon, M.R., The role of products as social stimuli: A symbolic interactionism perspective. Journal of Consumer research, 1983. 10(3): p. 319-329.

34. Lampinen, A., K. Huotari, and C. Cheshire, Challenges to Participation in the Sharing Economy: The Case of Local Online Peer-to-Peer Exchange in a Single Parents' Network. IxD\&A, 2015. 24: p. 16-32.

35. Belk, R.W., Extended self in a digital world. Journal of Consumer Research, 2013. 40(3): p. 477-500.

36. Böcker, L. and T. Meelen, Sharing for people, planet or profit? Analysing motivations for intended sharing economy participation. Environmental Innovation and Societal Transitions, 2017. 23: p. 28-39.

37. Tussyadiah, I.P., An exploratory study on drivers and deterrents of collaborative consumption in travel, in Information and communication technologies in tourism 2015. 2015, Springer. p. 817-830.

38. Huxley, P., et al., Development of a social inclusion index to capture subjective and objective life domains (phase II): Psychometric development study. Health Technology Assessment, 2012. 16(1): p. 1-248.

39. Diener, E., Subjective well-being: The science of happiness and a proposal for a national index. American psychologist, 2000. 55(1): p. 34.

40. Yang, S., et al., Why are customers loyal in sharing-economy services? A relational benefits perspective. Journal of Services Marketing, 2017. 31(1).

41. Hair, J.F., Multivariate data analysis. Seventh edition.. ed. 2014: Harlow, Essex : Prentice Hall.

42. Leana, C.R. and F.K. Pil, Social capital and organizational performance: Evidence from urban public schools. Organization Science, 2006. 17(3): p. 353-366.

43. Morales, A.C., Giving firms an " $E$ " for effort: Consumer responses to higheffort firms. Journal of Consumer Research, 2005. 31(4): p. 806-812.

44. Suh, A. and K.-S. Shin, Exploring the effects of online social ties on knowledge sharing: A comparative analysis of collocated vs dispersed teams. Journal of Information Science, 2010. 36(4): p. 443-463. 
45. Snelgar, R.S., Egoistic, altruistic, and biospheric environmental concerns: Measurement and structure. Journal of environmental psychology, 2006. 26(2): p. 87-99.

46. Rintamäki, T., et al., Decomposing the value of department store shopping into utilitarian, hedonic and social dimensions: Evidence from Finland. International Journal of Retail \& Distribution Management, 2006. 34(1): p. 624.

47. Ajzen, I. and M. Fishbein, Understanding attitudes and predicting social behaviour. 1980.

48. Taylor, S. and P.A. Todd, Understanding information technology usage: A test of competing models. Information systems research, 1995. 6(2): p. 144176.

49. Riemenschneider, C.K., D.A. Harrison, and P.P. Mykytyn, Understanding IT adoption decisions in small business: integrating current theories. Information \& management, 2003. 40(4): p. 269-285.

50. Venkatesh, V., J.Y. Thong, and X. Xu, Consumer acceptance and use of information technology: extending the unified theory of acceptance and use of technology. 2012.

51. Richardson, L. and J. Le Grand, Outsider and insider expertise: the response of residents of deprived neighbourhoods to an academic definition of social exclusion. Social Policy \& Administration, 2002. 36(5): p. 496-515.

52. Diener, E., et al., New well-being measures: Short scales to assess flourishing and positive and negative feelings. Social Indicators Research, 2010. 97(2): p. 143-156.

53. Möhlmann, M., Collaborative consumption: determinants of satisfaction and the likelihood of using a sharing economy option again. Journal of Consumer Behaviour, 2015. 14(3): p. 193-207.

54. Burroughs, J.E. and A. Rindfleisch, Materialism and well-being: A conflicting values perspective. Journal of Consumer research, 2002. 29(3): p. 348-370. 